\title{
The Effects of Nurse-Led Multidisciplinary Team Management on Glycosylated Hemoglobin, Quality of Life, Hospitalization, and Help-Seeking Behavior of People with Diabetes Mellitus
}

\author{
Yunxia Ni $\mathbb{D}^{1},{ }^{1}$ Suzhen Liu $\mathbb{D},{ }^{1}$ Jiping Li $\mathbb{D},{ }^{1}$ Ting Dong, $^{1}$ Lin Tao, ${ }^{1}$ Li Yuan, ${ }^{2}$ and Meilan Yang ${ }^{3}$ \\ ${ }^{1}$ West China Hospital/West China School of Nursing, Sichuan University, Chengdu, Sichuan Province, China \\ ${ }^{2}$ Department of Endocrinology, West China Hospital, Sichuan University, Chengdu, Sichuan Province, China \\ ${ }^{3}$ Yulin Community Health Service Center, Chengdu, Sichuan Province, China
}

Correspondence should be addressed to Suzhen Liu; yly90777@163.com and Jiping Li; jp-li@163.com

Received 13 June 2019; Revised 13 November 2019; Accepted 11 December 2019; Published 21 December 2019

Academic Editor: Valentino Cherubini

Copyright (c) 2019 Yunxia Ni et al. This is an open access article distributed under the Creative Commons Attribution License, which permits unrestricted use, distribution, and reproduction in any medium, provided the original work is properly cited.

\begin{abstract}
Aim. To evaluate the effect of community-nurse-led multidisciplinary team management on glycosylated hemoglobin (HbAlc), quality of life (QOL), hospitalization, and help-seeking behavior in people with type 2 diabetes mellitus (DM). Methods. A quasi-experimental trial was conducted among people with type $2 \mathrm{DM}$ from two community centers in China. The intervention group $(n=88)$ received community-nurse-led multidisciplinary team management for 2 years, while the control group $(n=91)$ received usual care. Data regarding HbAlc, QOL (assessed by the SF-36), hospitalization, and help-seeking behavior were collected at baseline and at 6,12, and 24 months. Results. During the 24-month project, the intervention group demonstrated $1.08 \%$ reduction in $\mathrm{HbAlc}$, whereas the control group achieved an increase of $0.45 \%$. The differences between the two groups were statistically significant $(P<0.001)$. The intervention group showed greater increased in QOL scores (from 66.43 to 70.47, $P<0.001)$, more decrease in hospitalization $(\mathrm{OR}=2.981,95 \% \mathrm{CI}: 1.016,8.752$ versus $\mathrm{OR}=1.189,95 \% \mathrm{CI}: 0.411,3.444 ; P=0.028)$ when compared with the control group. The percentage increase of seeking help from nurses in the intervention group (from $12.5 \%$ to $57.3 \%, P<0.001$ ) was significantly greater than that in the control group after the intervention. Conclusions. Nurse-led multidisciplinary team management is an effective intervention for improving glycemic control, QOL, hospitalization, and help-seeking behavior for people with DM in a community.
\end{abstract}

\section{Introduction}

Diabetes mellitus $(\mathrm{DM})$ is one of the most common chronic diseases in the world. There are more than 463 million diabetics worldwide at present, and with the incidence of this disease increasing, this number is expected to exceed 700 million by 2045 [1]. China has the largest number of diabetics, and the prevalence of DM has been conservatively reported to be approximately $11.6 \%$ [2]. Due to the insidious progress of microvascular and macrovascular complications in DM, patients may go undetected, resulting in multiple complications, including retinopathy, nephropathy, neuropathy, limb amputation, and stroke [3-5], which can lead to a serious social and economic burden $[6,7]$.
Previous research has suggested that community-based adaptions of DM intervention programs can help patients achieve meaningful glycemic decreases and healthy lifestyles at a lower overall cost $[8,9]$. Currently, most type 2 diabetics receive their care from primary care physicians, resulting in an increasingly heavy workload for physicians [10]. Primary care physicians have typically performed various duties, thus leading to time-limited visits for patients [11]. In addition, the nurses' autonomy and level of intervention depended on the primary care physician. Hence, numerous interventions have been explored to address the challenges of inadequate control with increasing patients [12-14]. As a consequence, many researchers extended the role of nurses by instituting them as care managers [15-17]. 
Studies of nurse-led management for people with DM have shown significant improvement in self-management and clinical outcomes $[15,16,18]$. Sadly, according to some studies, the leadership role of nurses has been overemphasized, leading to neglect of the importance of multidisciplinary teams. Quite a few teams were only made up of nurses and community health workers, sometimes including primary care physicians or pharmacists rather than multidisciplinary teams $[15,16,19]$. Even for multidisciplinary team management, the central role was usually played by primary care physicians or specialists instead of nurses [20-22]. Furthermore, the duration of follow-up was usually less than one year, long-term effects of nurse-led multidisciplinary team were scarce $[19,23]$. Although patients were uniquely qualified to say whether the intervention was acceptable or suitable for them [24, 25], most studies only focused on the effects of clinical outcomes or self-care. Thus, evaluating the effects from the distinctive perspective of patients was essential to better understand the patients' acceptance. Hence, our study explored the effects of help-seeking behavior changes after the nurseled management.

This study aimed to evaluate the effect of nurse-led multidisciplinary team management on hospitalization reduction, help-seeking behavior changes, and quality of life (QOL) in patients with type $2 \mathrm{DM}$ for 24 months.

\section{Methods}

2.1. Design. People with type $2 \mathrm{DM}$ were recruited by convenience sampling from outpatient department of Yulin and Tiaosanta Community Centers in Wuhou District, Chengdu City, China. For this quasi-experimental study, participants were assigned based on their residence address: patients who came from Yulin Community Center were assigned to the intervention group and those who came from Tiaosanta Community Center were assigned to the control group. This prospective clinical trial was conducted from 2014 to 2016.

2.2. Participants. The inclusion criteria of participants were as follows: (1) documented diagnosis of type $2 \mathrm{DM}$; (2) age $\geq 35$ years old (governmental requirement for management in community centers); (3) voluntary participation in the study; (4) ability to communicate; and (5) availability for contact by telephone at home. The exclusion criteria were as follows: (1) current pregnancy or planned pregnancy; (2) serious complications or comorbidity; (3) limitation of activities; (4) mental disorders; (5) recent cardiovascular event (<6 months before inclusion); and (6) simultaneous participation in other research studies.

Our sample size was based on the following assumptions. Assuming a $2 \%$ glycosylated hemoglobin (HbAlc) decrease in the intervention group, a $0.8 \% \mathrm{HbA} 1 \mathrm{c}$ decrease in the control group, and a power level of $95 \%$, a sample of 71 patients was estimated. We estimated a $20 \%$ discontinuation rate, and ultimately, a required sample size of 86 was calculated for each group.
2.3. Intervention. Nurse-led multidisciplinary team management consisted of three main intervention modes:

1. A series of health education classes delivered in a group education format

2. Individualized counseling via telephone and face-toface follow-up visit

3. Pamphlet and self-monitoring workbook were hand out

The intervention group received nurse-led multidisciplinary team management for 2 years. The multidisciplinary team was composed of large teaching hospital specialists (endocrinologists, dietitians, psychologists, cardiologists, nephrologists, and specialist nurses), one general practitioner, and four community nurses. Nurses went through a training program that included theoretical input (20 hours), practical training with endocrinology in the hospital (1 month), individual self-study, and review (varying lengths of training). The community nurse not only played a central role on the team in developing and conducting a patientspecific management plan but also served as a liaison between participants and primary care physicians. Nurses and primary care physicians provided referrals to a specialist service for participants.

Periodic group education involved about monthly 90minute sessions organized by nurses ( 6 months as one period over the course of 4 periods, five sessions per period). Thus, a total of 20 group education sessions were performed during 2 years. Session topics included a definition of diabetes, target ranges for essential results (glucose, blood pressure, lipids, weight), basic nutrition concepts, exercise strategies, medicine adherence, self-monitoring of blood glucose, smoking cessation, symptoms of acute and chronic complications, and emotion management. The contents of the classes were similar over all four periods but became more in-depth and practical over time to reinforce self-management skills.

Nurses tracked participants' self-management progress to determine the delivered dose of the intervention. Participants who reached the goal made by nurses and patients themselves received one telephone follow-up visit and one face-to-face individual counseling each month, to identify barriers and issues, assist in problem-solving, and provide feedback to primary care physicians. Those participants not making progress toward their goal levels received more frequent telephone follow-ups or home visits on average twice a month. Documents designed to record follow-up information for every participant were important to ensure intervention fidelity and provided a place to take notes on participants' goals, potential barriers, management plans, and strategies to overcome difficulties. This work was completed during the counseling or follow-up sessions. For participants suffering from serious problems (for instance, psychological problems, retinopathy, and nephropathy), nurses referred them to other members of the multidisciplinary team and kept track of the problem.

Participants also received a pamphlet developed specifically for the program as a guide to self-care (strategies for caloric control, physical activity, customized tips for taking 
medicine, and mental accommodation). They also received a self-monitoring workbook to record their daily nutrition intake, activities, and blood glucose.

Participants in the control group received usual care from their primary care physician, including educational classes 2 to 3 times per year, on average, and routine faceto-face follow-up at least 4 times per year. Medications were prescribed and adjusted based on the sole clinical judgment of the physician. Aside from performing the BP and blood glucose measurements when patients came to the community center for office visits, nurses rarely participated in DM management.

2.4. Data Collection. Data collection consisted of three parts as follows: (1) baseline demographic information collected through interviewing the patient was completed before the intervention; (2) the QOL, hospitalization, and help-seeking behavior were completed before, 6 months, 12 months, and 24 months after the intervention; and (3) HbAlc levels were measured before, 6 months, 12 months, and 24 months after the intervention.

2.4.1. HbA1c. HbAlc assays were conducted in the same laboratory using latex agglutination turbidimetric method with Hitachi 7600-020 automatic biochemical analyzer (Hitachi Company, Tokyo).

2.4.2. Questionnaires. Questionnaires used in this study consisted of researcher-designed questionnaire regarding demographic, hospitalization, help-seeking behavior, and the 36item Short-Form Health Survey (SF-36) for the QOL. The SF-36 questionnaire provides a profile of eight subscales that measure physical functioning, role-physical, bodily pain, general health, vitality, social functioning, role-emotional, and mental health. A $0-100$ standardized score is ultimately presented. The higher score indicates better health conditions. The validity and reliability of this questionnaire were evaluated in Chinese population and reported the Cronbach's $\alpha$ coefficient ranging from 0.77 to 0.88 [26]. Hospitalization data were obtained through patient-reported number of hospitalizations caused by diabetes during the past 6 months. Help-seeking behaviors were identified via one question "when you have problems related to diabetes, who are you seeking for help?" Patients made choices from the following options: doctors, nurses, or others. Multiple choices were accepted.

2.5. Statistical Analysis. Data were analyzed by the SPSS version 19.0 software (IBM Corporation, Armonk, NY, USA). Statistical tests were used to study differences in baseline demographic with a $t$ test used for continuous variables and a chi-squared test for categorical variables. The primary outcomes were changes from baseline to 24 months in HbAlc, QOL, hospitalizations, and help-seeking behaviors. General linear mixed models (for continuous variables) and generalized estimating equations (GEE) (for categorical variables) were used to examine the effectiveness of the program, controlling for the covariates of age, gender, diabetes complications, and treatment modality. Intention-to-treat (ITT) analyses were conducted, and values were imputed to replace missing data, as indicated previously. A significance level of $5 \%$ (two-tailed) was used for all tests.

2.6. Ethical Considerations. This study was approved by the ethics committee of West China Hospital of Sichuan University (no. 2015-110). Information and explanation of the ethical observations of the study were provided to the subjects, and they were asked to sign a consent form. The patients were free to withdraw from the study at any time, and all data were maintained confidentially.

\section{Results}

3.1. Participant Demographic Characteristics. One hundred seventy-nine participants were enrolled in this study: 88 in the intervention group and 91 in the control group. Figure 1 shows the flow of patients through the study. In total, 13 patients $(7.3 \%)$ were lost to follow-up (6 patients came from the intervention group and 7 from the control group). The characteristics of the participants are shown in Table 1. The intervention and control groups were well matched on most variables with the exception of age distribution, $\mathrm{HbAlc}$, QOL, and hospitalizations. Nearly half patients $(46.6 \%)$ in the intervention group were older than 70 years; however, $49.4 \%$ of patients in the control group were between 60 and 70 years old. Age distribution could be operating in unmatched $\mathrm{HbAlc}$, QOL, and hospitalizations.

3.2. HbAlc and QOL. The HbAlc in the intervention group decreased from $7.08 \%$ to $6.03 \%$, with a reduction of $1.08 \%$, while the control group showed an increase of $0.45 \%$ (Table 2). The differences between the two groups were statistically significant $(P<0.001)$. Mean score changes of QOL in the intervention group showed greater increased than those in the control group $(P<0.001)$ (Table 2).

3.3. Hospitalizations. The intervention group had nearly triple the risk of the hospitalizations compared with those in the control group before the intervention (Table 3). The odds ratio of hospitalizations decreased to 1.189 after the intervention. There was a statistically significant difference regarding the hospitalizations changes between two groups according to the generalized estimating equations (Wald $\chi^{2}=4.83$, $P=0.028)$.

3.4. Help-Seeking Behavior. When patients have difficulty in controlling diabetes, most of them seek help from doctors firstly instead of nurses for both groups at baseline (Table 4). At 24 months, 57.3\% patients reported that they were willing to seek help from nurses in the intervention group. This percentage increase of seeking help from nurses in the intervention group was significantly greater than the increase in the control group ( $44.8 \%$ versus $8.1 \%, P<0.001$ ). The percentages of seeking help from doctors were decreased for both groups, but there was no statistically significant.

\section{Discussion}

The results of our study revealed that the nurse-led multidisciplinary team management leads to significant improving 


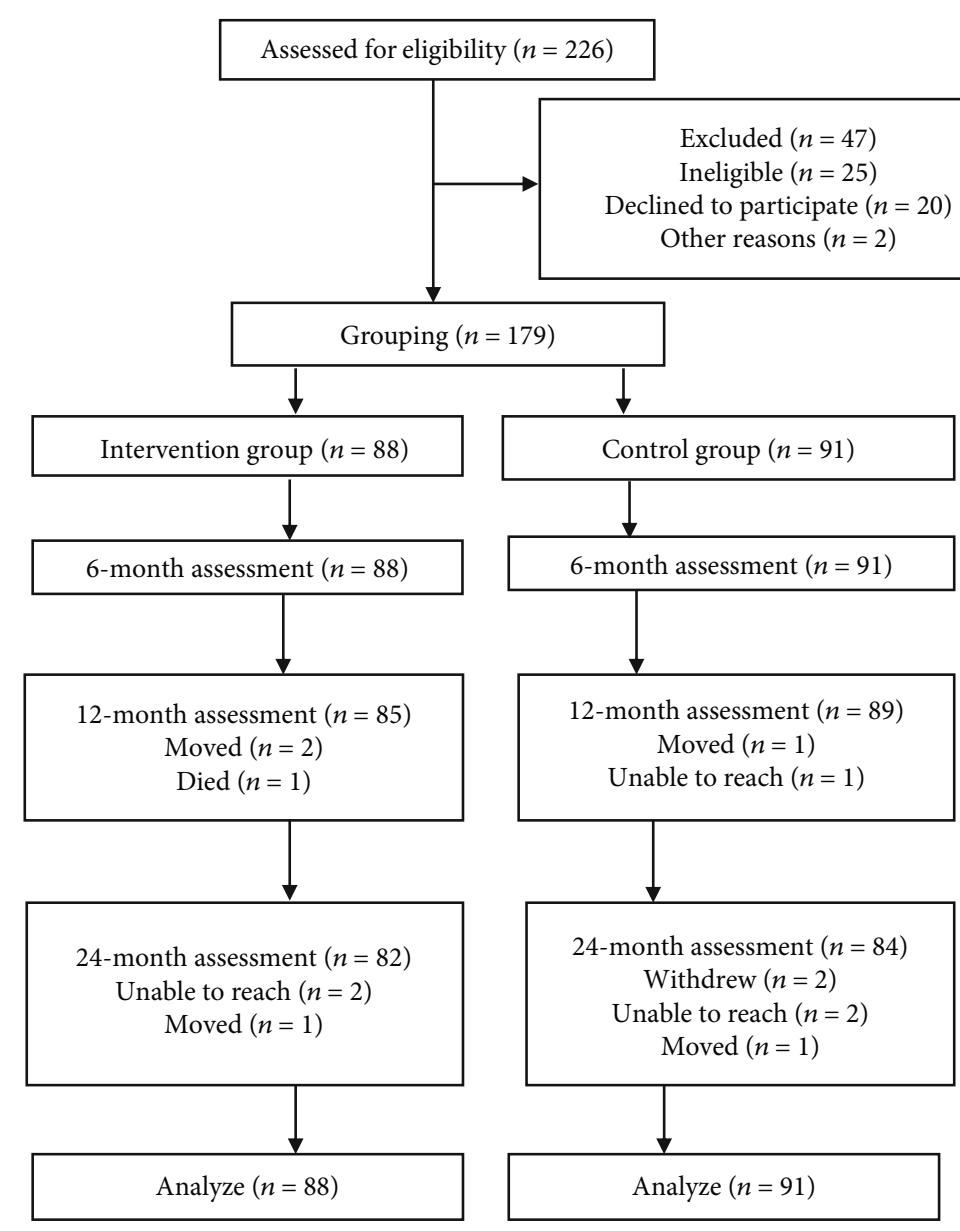

FIGURE 1: Flow diagram of participants through each stage of the trial.

effects on HbA1c, QOL, hospitalizations, and help-seeking behavior changes. The study has several design and community-based methodological strengths. The intervention lasted for 2 years, allowing us to document the sustained effects. In addition, we first tested the intervention effects related to the participants' help-seeking behavior in their truest sense. Moreover, the community was close with local large teaching hospital and local health-care providers, resulting in timely care delivered to the participants and effective communication with team members. Furthermore, nurses as the core of the team were they themselves are part of the community, making it feasible to reform routine management in the future.

Although the control group showed a good glucose control and remained excellent until the end of the study, the intervention group reduction rates were especially noteworthy. The reductions in the intervention group were sustained over the course of 24 months, with evidence of further potential reductions if the intervention continued beyond the study period. Furthermore, the $\mathrm{HbAlc}$ reductions in the intervention group were not only statistically significant but also clinically significant. At 6 months after the intervention, the $\mathrm{HbA} 1 \mathrm{c}$ in the intervention group has reached Chinese guideline goals $(<7.0 \%)$, followed by sustained improvement during the 18-month maintenance period, which strongly suggests a clinical impact of the nurse-led team management.
The results of our study were consistent with the results of other studies showing that nurse-led management has an improving impact on the $\mathrm{HbAlc}$ of the patients with type 2 DM [27-29]. However, it is noticeable that these studies had been only performed by nurses or nurse-community health workers team, while the management team of the current study was made up by multidisciplinary specialists. In a meta-analysis of 34 trials by nurse-led self-management education, the HbAlc level decreased by a mean of $0.7 \%$ [30], which showed less decline than our study. This difference could be explained by the duration of follow-up of the studies involved in the meta-analysis being usually less than 1 year, while our study performed the longer term to see the intervention impact.

Our findings confirmed the findings of previous studies $[28,31,32]$ that nurse-led management improved the QOL of people with DM. However, the improvement had not been found in a trial by Blackberry et al. [16], which was in contrast to our findings. A possible reason for negative result may be the low intensity of their coaching and low patient participation. Ideally, nurses were supposed to provide eight telephone follow-up visits and one face-to-face coaching for each patient. In fact, patients only received a median of three telephone calls; what is more, a quarter of patients in the intervention group did not receive any telephone coaching. In our study, a more intensive intervention with more 
Table 1: Patient demographic characteristics at baseline.

\begin{tabular}{|c|c|c|c|c|}
\hline Variable & $\begin{array}{c}\text { All } \\
(N=179)\end{array}$ & $\begin{array}{l}\text { Intervention } \\
\quad(n=88)\end{array}$ & $\begin{array}{l}\text { Control } \\
(n=91)\end{array}$ & $P$ value \\
\hline Age, y, mean (SD) & $66.5(8.9)$ & $66.4(10.6)$ & $66.6(7.0)$ & 0.866 \\
\hline Age, y, $n(\%)$ & & & & 0.014 \\
\hline$<50$ & $7(3.9)$ & $6(6.8)$ & $1(1.1)$ & \\
\hline $50 \sim<60$ & $28(15.6)$ & $16(18.2)$ & $12(13.2)$ & \\
\hline $60 \sim<70$ & $70(39.1)$ & $25(28.4)$ & $45(49.4)$ & \\
\hline$\geq 70$ & $74(41.3)$ & $41(46.6)$ & $33(36.3)$ & \\
\hline Gender, $n(\%)$ & & & & 0.610 \\
\hline Female & $95(53.1)$ & $45(51.1)$ & $50(54.9)$ & \\
\hline Male & $84(46.9)$ & $43(48.9)$ & $41(45.1)$ & \\
\hline Spouse, $n(\%)$ & & & & 0.948 \\
\hline Yes & $165(92.2)$ & $81(92.0)$ & $84(92.3)$ & \\
\hline No & $14(7.8)$ & $7(8.0)$ & $7(7.7)$ & \\
\hline Education level, $n(\%)$ & & & & 0.397 \\
\hline No schooling & $35(19.5)$ & $16(18.1)$ & $19(20.8)$ & \\
\hline Junior/middle school & $51(28.5)$ & $21(23.9)$ & $30(33.0)$ & \\
\hline High school & $56(31.3)$ & $32(36.4)$ & $24(26.4)$ & \\
\hline Some college or above & $37(20.7)$ & $19(21.6)$ & $18(19.8)$ & \\
\hline Employment status, $n(\%)$ & & & & 0.133 \\
\hline Employed & $20(11.2)$ & $13(14.8)$ & $7(7.7)$ & \\
\hline Retired or unemployed & $159(88.8)$ & $75(85.2)$ & $84(92.3)$ & \\
\hline Basic medical insurance, $n(\%)$ & & & & 0.240 \\
\hline Yes & $177(98.9)$ & $86(97.7)$ & $91(100.0)$ & \\
\hline No & $2(1.1)$ & $2(2.3)$ & $0(0.0)$ & \\
\hline Additional medical insurance, $n(\%)$ & & & & 0.754 \\
\hline Yes & $122(68.2)$ & $59(67.0)$ & $63(69.2)$ & \\
\hline No & $57(31.8)$ & $29(33.0)$ & $28(30.8)$ & \\
\hline Monthly income, $n(\%)$ & & & & 0.308 \\
\hline$¥ \leq 1500$ & $30(16.7)$ & $14(15.9)$ & $16(17.6)$ & \\
\hline$¥ 1501-4500$ & $146(81.6)$ & $74(84.1)$ & $72(79.1)$ & \\
\hline$¥>4500$ & $3(1.7)$ & $0(0.0)$ & $3(3.3)$ & \\
\hline \multicolumn{5}{|l|}{ Diabetes complications } \\
\hline Yes & $70(39.1)$ & $39(44.3)$ & $31(34.1)$ & 0.160 \\
\hline No & $109(60.9)$ & $49(55.7)$ & $60(65.9)$ & \\
\hline \multicolumn{5}{|l|}{ Treatment modality } \\
\hline Diet/exercise & $6(3.4)$ & $2(2.3)$ & $4(4.4)$ & 0.286 \\
\hline Oral medication & $137(76.5)$ & $64(72.7)$ & $73(80.2)$ & \\
\hline Insulin therapy & $8(4.5)$ & $6(6.8)$ & $2(2.2)$ & \\
\hline Oral medication and insulin therapy & $28(15.6)$ & $16(18.2)$ & $12(13.2)$ & \\
\hline HbAlc, \%, mean $(S D)$ & & $7.08(1.26)$ & $6.34(1.02)$ & $<0.001$ \\
\hline QOL, mean (SD) & & $66.43(14.07)$ & $74.71(14.09)$ & $<0.001$ \\
\hline Hospitalizations, $n(\%)$ & & $13(14.8)$ & $5(5.5)$ & 0.039 \\
\hline
\end{tabular}

SD: standard deviation; HbAlc: glycosylated hemoglobin; QOL: quality of life.

frequent calls and face-to-face counselling and with longer interaction was performed, helping to highlight the effect of the intervention.

Despite the hospitalizations of participants in the intervention group, they showed a higher risk than those in the control group; the risk of hospitalizations had significant reduction, which demonstrated that the nurse-led management was effective on hospitalization reduction, keeping with the findings from previous studies [33-35]. Davidson et al. assessed the hospitalizations before and after the 
TABLE 2: Changes in HbA1c and QOL scores between the two groups.

\begin{tabular}{|c|c|c|c|c|}
\hline Outcomes & $\begin{array}{l}\text { Intervention group } \\
\quad(\text { mean } \pm S D)\end{array}$ & $\begin{array}{l}\text { Control group } \\
\text { (mean } \pm S D)\end{array}$ & $\begin{array}{l}\text { Estimated between-group } \\
\text { difference* }(95 \% \mathrm{CI})\end{array}$ & $P$ value $^{\Delta}$ \\
\hline Change in HbAlc (\%) & -1.08 & 0.45 & $-1.53(-1.91,-1.14)$ & $<0.001^{\diamond}$ \\
\hline Baseline & $7.08 \pm 1.26$ & $6.34 \pm 1.02$ & $0.74(0.41,1.09)$ & \\
\hline 6 months & $6.72 \pm 0.97$ & $6.14 \pm 1.02$ & $0.58(0.28,0.87)$ & \\
\hline 12 months & $6.22 \pm 1.46$ & $6.26 \pm 1.17$ & $-0.04(-0.44,0.36)$ & \\
\hline 24 months & $6.03 \pm 1.02$ & $6.68 \pm 1.48$ & $-0.65(-1.04,-0.26)$ & \\
\hline Change in QOL score & 4.04 & -5.10 & $9.14(1.21,17.07)$ & $<0.001^{\diamond}$ \\
\hline Baseline & $66.43 \pm 14.07$ & $74.71 \pm 14.09$ & $-8.27(-12.43,-4.12)$ & \\
\hline 6 months & $71.57 \pm 14.65$ & $74.89 \pm 12.62$ & $-3.31(-7.34,0.71)$ & \\
\hline 12 months & $72.82 \pm 13.90$ & $73.45 \pm 13.26$ & $-1.18(-6.56,4.21)$ & \\
\hline 24 months & $70.47 \pm 13.75$ & $69.61 \pm 14.43$ & $0.86(-6.24,7.97)$ & \\
\hline
\end{tabular}

SD: standard deviation; HbAlc: glycosylated hemoglobin; QOL: quality of life; CI: confidence interval. * Reference is the control group; ${ }^{{ } \text {intention-to-treat }}$ analysis using general linear mixed model with group; time, group $\times$ time effects, and covariates of age, gender, diabetes complications, and treatment modality. ${ }^{\circ}$ Overall effect $P$ value.

TABLE 3: Changes in hospitalizations between the two groups.

\begin{tabular}{|c|c|c|c|c|c|c|}
\hline \multirow{2}{*}{ Hospitalizations, $n(\%)$} & \multirow{2}{*}{ Intervention group } & \multirow{2}{*}{ Control group } & \multirow{2}{*}{ OR } & \multirow{2}{*}{$95 \% \mathrm{CI}$} & \multicolumn{2}{|c|}{ GEE } \\
\hline & & & & & Wald $\chi^{2}$ & $P$ value* \\
\hline Baseline & $13(14.8)$ & $5(5.5)$ & 2.981 & $1.016-8.752$ & 4.83 & $0.028^{\Delta}$ \\
\hline 6 months & $12(13.6)$ & $7(7.7)$ & 1.895 & $0.709-5.061$ & & \\
\hline 12 months & $10(11.8)$ & $4(4.5)$ & 2.833 & $0.853-9.411$ & & \\
\hline 24 months & $8(9.8)$ & $7(8.3)$ & 1.189 & $0.411-3.444$ & & \\
\hline
\end{tabular}

OR: odds ratio; CI: confidence interval; GEE: generalized estimating equations. ${ }^{*}$ Generalized estimating equations were used to analyze, with covariates of age, gender, diabetes complications, and treatment modality. ${ }^{\Delta}$ Intervention effect $P$ value.

TABLE 4: Changes in help-seeking behavior between the two groups.

\begin{tabular}{|c|c|c|c|c|}
\hline \multirow{2}{*}{ Help-seeking behavior, $n(\%)$} & \multirow{2}{*}{ Intervention group } & \multirow{2}{*}{ Control group } & \multicolumn{2}{|c|}{ GEE } \\
\hline & & & Wald $\chi^{2}$ & $P$ value* \\
\hline Percentage change in help-seeking from doctors & -10.4 & -1.1 & 1.25 & $0.263^{\Delta}$ \\
\hline Baseline ${ }^{\#}$ & $65(73.9)$ & $66(72.5)$ & & \\
\hline 6 months & $66(75.0)$ & $69(75.8)$ & & \\
\hline 12 months & $59(69.4)$ & $65(73.0)$ & & \\
\hline 24 months & $52(63.4)$ & $60(71.4)$ & & \\
\hline Percentage change in help-seeking from nurses & 44.8 & 8.1 & 19.36 & $<0.001^{\Delta}$ \\
\hline Baseline ${ }^{\#}$ & $11(12.5)$ & $11(12.1)$ & & \\
\hline 6 months & $28(31.8)$ & $16(17.6)$ & & \\
\hline 12 months & $35(41.2)$ & $17(19.1)$ & & \\
\hline 24 months & $47(57.3)$ & $17(20.2)$ & & \\
\hline Percentage change in help-seeking from others & 0.1 & -6.6 & 0.05 & $0.832^{\Delta}$ \\
\hline Baseline $e^{\#}$ & $15(17.0)$ & $19(20.9)$ & & \\
\hline 6 months & $19(21.6)$ & $20(22.0)$ & & \\
\hline 12 months & $23(27.1)$ & $18(20.2)$ & & \\
\hline 24 months & $14(17.1)$ & $12(14.3)$ & & \\
\hline
\end{tabular}

GEE: generalized estimating equations. ${ }^{*}$ Generalized estimating equations were used to analyze, with covariates of age, gender, diabetes complications, and treatment modality. ${ }^{\triangle}$ Intervention effect $P$ value; ${ }^{\#}$ there were no significant differences between the two groups at baseline.

intervention, without control group; moreover, the program was performed in a minority population [33], which was different from our study. We set up a control group and evalu- ate the intervention effect using the generalized estimation equation, showing rigorous methodology, further revised, and replenished previous studies. 
The help-seeking behavior has changed after the intervention, and more percentage of the participants in the intervention group compared with the control group were willing to seek help from nurses. To some extent, it suggested that nurses get more trust from participants. Only when participants trust in the nurses' experience with DM management will they seek help from nurses $[36,37]$. On the other hand, although the percentage reduction of seeking help from doctors showed no statistical significance, the overall trend of reduction was sustained. This trend revealed that some DM-related problems patients suffered could be solved by nurses [38], and there was no need to seek help from doctors, contributing to utilizing health-care resources efficiently, evolving the role of nurses appropriately $[39,40]$, and relieving the pressure of health care finally $[41,42]$. Moreover, the help-seeking behavior changes demonstrated the acceptance of nurse-led management. In a cross-section study Lutfiyya et al., they analyzed the Medicare claims data, people with DM in the nurse practitioner only group had significantly improved outcomes compared with all primary care physician provider groups regarding health-care services utilization [43]. Consequently, nurse-led management for DM in primary setting was associated with more proper health care utilization.

This study has several limitations. First, to avoid contamination of intervention effects between groups, we allocated patients to groups by geographical distance of two community centers, with nonrandomized method. Second, this study was a single-center program in only one region, and further research can be conducted in multiple centers. Finally, the hospitalizations were patient-reported, which may have led to recall bias. Future studies should consider addressing this bias through medical records to collect data.

\section{Conclusions}

The implementation of nurse-led team management proves to be practical and feasible in community settings and is accompanied by favorable $\mathrm{HbAlc}$, improved QOL, hospitalizations, and help-seeking behavior. It expanded the role of nurses in helping DM achieving an excellent glucose control, seeking help reasonably. In addition, we consider the intervention as a new approach for Chinese community management to address the shortage of primary care physicians. It is not known whether the nurse-led management has impact on cost-effectiveness in patients with DM.

\section{Data Availability}

The data used to support the findings of this study are available from the corresponding author upon request.

\section{Conflicts of Interest}

The authors declare that they have no conflicts of interest.

\section{Acknowledgments}

This study was supported by the China Medical Board (No. 11-085). We thank the patients who participated in the program and the administration and staff of the two community centers for their collaboration to the program. We also thank Prof. Deying Kang for the assistance in the data analysis.

\section{References}

[1] International Diabetes Federation Atlas, "IDF Diabetes Atlas," 9th edition, December 2019,http://www.diabetesatlas.org/.

[2] Y. Xu, L. Wang, J. He et al., "Prevalence and control of diabetes in Chinese adults," JAMA, vol. 310, no. 9, pp. 948-959, 2013.

[3] E. W. Gregg, N. Sattar, and M. K. Ali, "The changing face of diabetes complications," The Lancet Diabetes and Endocrinology, vol. 4, no. 6, pp. 537-547, 2016.

[4] C. P. Shearman and R. Windhaber, "Foot complications in patients with diabetes," Surgery, vol. 28, no. 6, pp. 288-292, 2010.

[5] S. Matsunaga, S. Tanaka, K. Fujihara et al., "Association between all-cause mortality and severity of depressive symptoms in patients with type 2 diabetes: Analysis from the Japan Diabetes Complications Study (JDCS)," Journal of Psychosomatic Research, vol. 99, pp. 34-39, 2017.

[6] C. Bommer, E. Heesemann, V. Sagalova et al., "The global economic burden of diabetes in adults aged 20-79 years: a cost-ofillness study," The Lancet Diabetes and Endocrinology, vol. 5, no. 6, pp. 423-430, 2017.

[7] E. Pagano, M. De Rosa, E. Rossi et al., "The relative burden of diabetes complications on healthcare costs: the populationbased CINECA-SID ARNO diabetes observatory," Nutrition, Metabolism, and Cardiovascular Diseases, vol. 26, no. 10, pp. 944-950, 2016.

[8] E. Gucciardi, S. Espin, A. Morganti, and L. Dorado, "Implementing specialized diabetes teams in primary care in Southern Ontario," Canadian Journal of Diabetes, vol. 39, no. 6, pp. 467-477, 2015.

[9] J. K. Allen, C. R. Dennison Himmelfarb, S. L. Szanton, and K. D. Frick, "Cost-effectiveness of nurse practitioner/community health worker care to reduce cardiovascular health disparities," The Journal of Cardiovascular Nursing, vol. 29, no. 4, pp. 308-314, 2014.

[10] S. M. Petterson, W. R. Liaw, C. Tran, and A. W. Bazemore, "Estimating the residency expansion required to avoid projected primary care physician shortages by 2035," Annals of Family Medicine, vol. 13, no. 2, pp. 107-114, 2015.

[11] M. A. Kristensen and T. Thorsen, "Increasing shortage of general practitioners in social deprived Danish communities," Ugeskrift for laeger, vol. 176, no. 11, 2014.

[12] E. R. Lenz, M. O. Mundinger, S. C. Hopkins, S. X. Lin, and J. L. Smolowitz, "Diabetes care processes and outcomes in patients treated by nurse practitioners or physicians," The Diabetes Educator, vol. 28, no. 4, pp. 590-598, 2002.

[13] S. T. Houweling, N. Kleefstra, K. J. van Hateren, K. H. Groenier, B. Meyboom-de Jong, and H. J. Bilo, "Can diabetes management be safely transferred to practice nurses in a primary care setting? A randomised controlled trial," Journal of Clinical Nursing, vol. 20, no. 9-10, pp. 1264-1272, 2011. 
[14] P. J. Van der Wees, M. W. Friedberg, E. A. Guzman, J. Z. Ayanian, and H. P. Rodriguez, "Comparing the implementation of team approaches for improving diabetes care in community health centers," BMC Health Services Research, vol. 14, no. 1, p. 608, 2014.

[15] J. D. DePue, S. Dunsiger, A. D. Seiden et al., "Nurse-community health worker team improves diabetes care in American Samoa: results of a randomized controlled trial," Diabetes Care, vol. 36, no. 7, pp. 1947-1953, 2013.

[16] I. D. Blackberry, J. S. Furler, J. D. Best et al., "Effectiveness of general practice based, practice nurse led telephone coaching on glycaemic control of type 2 diabetes: the Patient Engagement and Coaching for Health (PEACH) pragmatic cluster randomised controlled trial," BMJ, vol. 347 , no. sep18 1, article f5272, 2013.

[17] P. I. Buerhaus, C. M. Des Roches, R. Dittus, and K. Donelan, "Practice characteristics of primary care nurse practitioners and physicians," Nursing Outlook, vol. 63, no. 2, pp. 144$153,2015$.

[18] L. Jutterström, Å. Hörnsten, H. Sandström, H. Stenlund, and U. Isaksson, "Nurse-led patient-centered self-management support improves $\mathrm{HbAlc}$ in patients with type 2 diabetes-a randomized study," Patient Education and Counseling, vol. 99, no. 11, pp. 1821-1829, 2016.

[19] G. Azami, K. L. Soh, S. G. Sazlina et al., "Effect of a nurseled diabetes self-management education program on glycosylated hemoglobin among adults with type 2 diabetes," Journal Diabetes Research, vol. 2018, article 4930157, pp. 1-12, 2018.

[20] F. Jiao, C. S. Fung, Y. F. Wan et al., "Effectiveness of the multidisciplinary risk assessment and management program for patients with diabetes mellitus (RAMP-DM) for diabetic microvascular complications: a population-based cohort study," Diabetes \& Metabolism, vol. 42, no. 6, pp. 424-432, 2016.

[21] H. S. Bajaj, R. Aronson, K. Venn, C. Ye, and M. E. Sharaan, "The need associated with diabetes primary care and the impact of referral to a specialist-centered multidisciplinary diabetes program (the NADIR study)," Canadian Journal of Diabetes, vol. 40, no. 2, pp. 120-125, 2016.

[22] S. A. Hollingworth, M. Donald, J. Zhang, B. P. Vaikuntam, A. Russell, and C. Jackson, "Impact of a general practitionerled integrated model of care on the cost of potentially preventable diabetes-related hospitalisations," Primary Care Diabetes, vol. 11, no. 4, pp. 344-347, 2017.

[23] J. C. Zgibor, M. A. Maloney, M. Malmi et al., "Effectiveness of certified diabetes educators following pre-approved protocols to redesign diabetes care delivery in primary care: results of the REMEDIES 4D trial," Contemporary Clinical Trials, vol. 64, pp. 201-209, 2018.

[24] A.-K. Fryer, M. W. Friedberg, and R. W. Thompson, "patient perceptions of integrated care and their relationship to utilization of emergency, inpatient and outpatient services," Healthcare, vol. 5, no. 4, pp. 183-193, 2017.

[25] K. J. Smith, G. Gariépy, and N. Schmitz, "Self-reported use of diabetes healthcare services in a Quebec community-based sample: impact of depression status," Public Health, vol. 128, no. 1, pp. 63-69, 2014.

[26] J. Hu, K. J. Gruber, and K. H. Hsueh, "Psychometric properties of the Chinese version of the SF-36 in older adults with diabetes in Beijing, China," Diabetes Research and Clinical Practice, vol. 88 , no. 3, pp. 273-281, 2010.
[27] I. Odnoletkova, G. Goderis, F. Nobels et al., "Optimizing diabetes control in people with type 2 diabetes through nurseled telecoaching," Diabetic Medicine, vol. 33, no. 6, pp. 777$785,2016$.

[28] M. T. Kim, K. B. Kim, B. Huh et al., "The effect of a community-based self-help intervention: Korean Americans with type 2 diabetes," American Journal of Preventive Medicine, vol. 49, no. 5, pp. 726-737, 2015.

[29] B. Daly, C. J. L. Tian, and R. K. R. Scragg, "Effect of nurse-led randomised control trials on cardiovascular risk factors and HbA1c in diabetes patients: a meta-analysis," Diabetes Research and Clinical Practice, vol. 131, pp. 187-199, 2017.

[30] J. K. Tshiananga, S. Kocher, C. Weber, K. Erny-Albrecht, K. Berndt, and K. Neeser, "The effect of nurse-led diabetes self-management education on glycosylated hemoglobin and cardiovascular risk factors: a meta-analysis," The Diabetes Educator, vol. 38, no. 1, pp. 108-123, 2012.

[31] M. Markle-Reid, J. Ploeg, K. D. Fraser et al., "Community program improves quality of life and self-management in older adults with diabetes mellitus and comorbidity," Journal of the American Geriatrics Society, vol. 66, no. 2, pp. 263-273, 2018.

[32] Y. Ronngren, A. Bjork, A. Audulv, I. Enmarker, L. Kristiansen, and D. Haage, "Educational nurse-led lifestyle intervention for persons with mental illness," International Journal of Mental Health Nursing, vol. 27, no. 3, pp. 1022-1031, 2018.

[33] M. B. Davidson, A. Ansari, and V. J. Karlan, "Effect of a nursedirected diabetes disease management program on urgent care/emergency room visits and hospitalizations in a minority population," Diabetes Care, vol. 30, no. 2, pp. 224-227, 2007.

[34] L. Min, C. T. Cigolle, S. J. Bernstein et al., "Diabetes care improvement in pharmacist- versus nurse-supported patientcentered medical homes," American Journal of Managed Care, vol. 23, no. 11, article e374, 2017.

[35] S. Maru, J. Byrnes, M. J. Carrington, Y. K. Chan, S. Stewart, and P. A. Scuffham, "Economic evaluation of a nurse-led home and clinic-based secondary prevention programme to prevent progressive cardiac dysfunction in high-risk individuals: the nurse-led intervention for less chronic heart failure (NILCHF) randomized controlled study," European Journal of Cardiovascular Nursing, vol. 17, no. 5, pp. 439-445, 2017.

[36] J. K. Green, R. L. Rothman, and K. L. Cavanaugh, "Patientprovider communication in patients with diabetes and depressive symptoms," Diabetes Research and Clinical Practice, vol. 95, no. 1, pp. e10-e13, 2012.

[37] R. L. Street, "How clinician-patient communication contributes to health improvement: modeling pathways from talk to outcome," Patient Education and Counseling, vol. 92, no. 3, pp. 286-291, 2013.

[38] N. A. Martínez-González, R. Tandjung, S. Djalali, and T. Rosemann, "The impact of physician-nurse task shifting in primary care on the course of disease: a systematic review," Human Resources for Health, vol. 13, no. 1, p. 55, 2015.

[39] M. Tabesh, D. J. Magliano, D. N. Koye, and J. E. Shaw, "The effect of nurse prescribers on glycaemic control in type 2 diabetes: a systematic review and meta-analysis," International Journal of Nursing Studies, vol. 78, pp. 37-43, 2018.

[40] Y. F. Kuo, N. W. Chen, J. Baillargeon, M. A. Raji, and J. S. Goodwin, "Potentially preventable hospitalizations in Medicare patients with diabetes: a comparison of primary care provided by nurse practitioners versus physicians," Medical Care, vol. 53, no. 9, pp. 776-783, 2015. 
[41] M. Crowe, V. Jones, M.-A. Stone, and G. Coe, "The clinical effectiveness of nursing models of diabetes care: a synthesis of the evidence," International Journal of Nursing Studies, vol. 93, pp. 119-128, 2019.

[42] P. Morgan, C. M. Everett, V. A. Smith et al., "Factors associated with having a physician, nurse practitioner, or physician assistant as primary care provider for veterans with diabetes mellitus," INQUIRY: The Journal of Health Care Organization, Provision, and Financing, vol. 54, no. 11, article 004695801771276, 2017.

[43] M. N. Lutfiyya, L. Tomai, B. Frogner, F. Cerra, D. Zismer, and S. Parente, "Does primary care diabetes management provided to Medicare patients differ between primary care physicians and nurse practitioners?," Journal of Advanced Nursing, vol. 73, no. 1, pp. 240-252, 2017. 


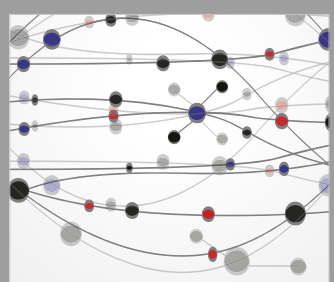

The Scientific World Journal
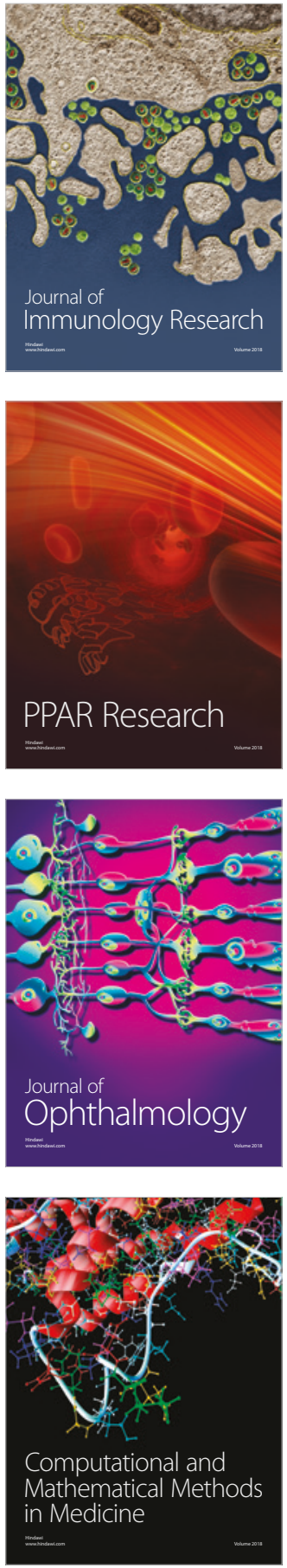

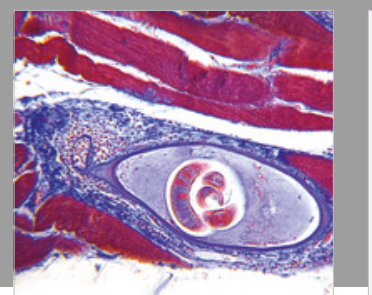

Gastroenterology Research and Practice

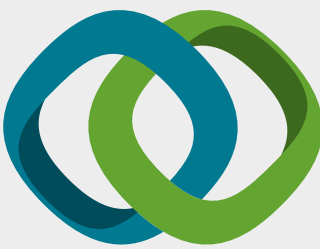

\section{Hindawi}

Submit your manuscripts at

www.hindawi.com
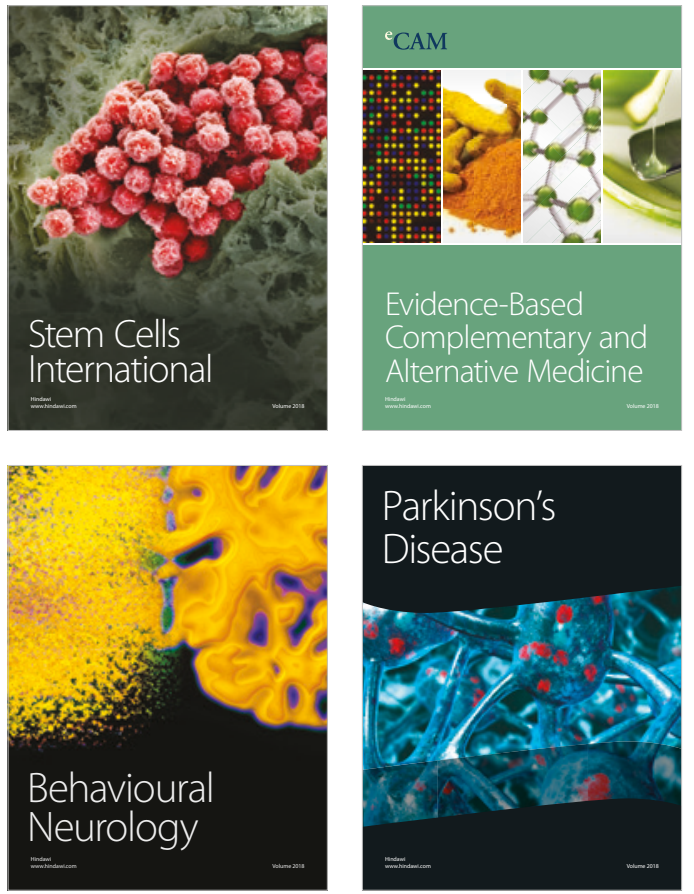

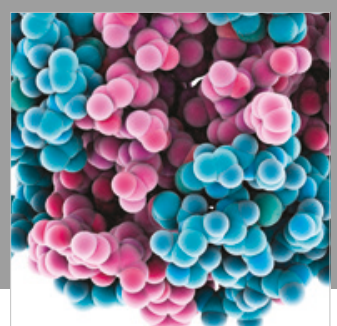

ournal of

Diabetes Research

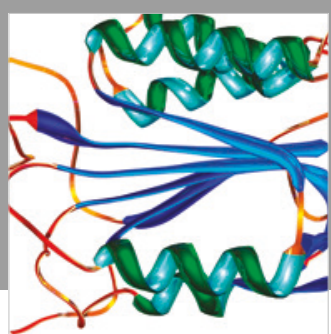

Disease Markers
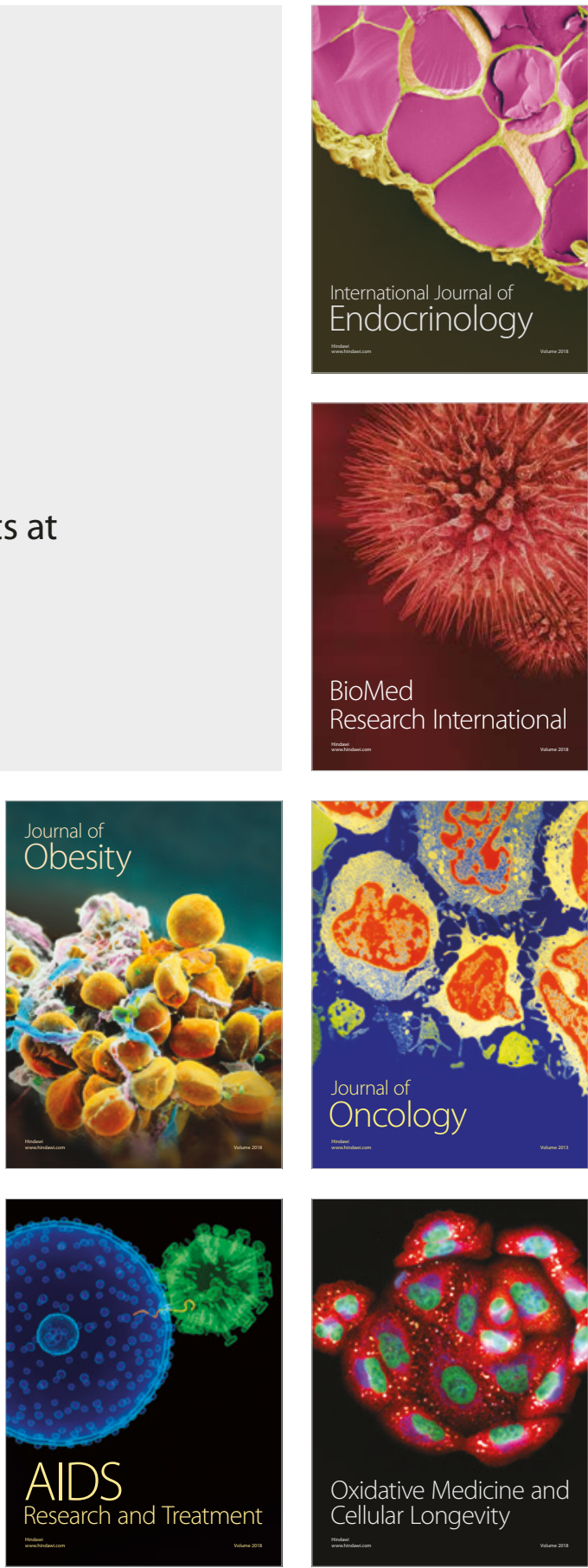